\title{
PENERAPAN METODE LATIHAN SINGLE LEG JUMP TERHADAP KEMAMPUAN FLYING SHOOT PEMAIN BOLA TANGAN
}

\author{
Ujang Rohman ${ }^{1)}$, Ramadhani Hananto Puriana ${ }^{2)}$ \\ ${ }^{1,2}$ Fakultas Keguruan dan Ilmu Pendidikan, \\ Universitas PGRI Adi Buana Surabaya \\ Email: ${ }^{1}$ ujang_roh64@unipasby.ac.id.,ramadhani@unipasby.ac.id ${ }^{2}$
}

\begin{abstract}
Abstrak
Penelitian mengenai penerapan metode latihan single leg jump ini bertujuan untuk membuktikan pengaruhnya terhadap kemampuan plying shoot pemain bola tangan. Metode penelitian menggunakan metode eksperimen melalui pendekatan kuantitatif yang dilakukan secara terstruktur mengenai deskripsi data metode latihan single leg jump pengaruh terhadap kemampuan plying shoot. Rancangan penelitian menggunakan One Group Pretest-Postest Design. Populasi mahasiswa Program Studi Pendidikan Jasmani, FKIP Universitas PGRI Adi Buana Surabaya, sedangkan sampel mahasiswa Pendidikan Jasmani angkatan 2017 ditentukan secara purposive berjumlah 20 orang. Hasil uji hipotesis menggunakan analisis uji-t (sign. 0.05) dan $d k=19$ ternyata nilai $t_{\text {hitung }}$ sebesar 2.26 dan $t_{\text {tabel }}$ sebesar 1.73. Hal ini menunjukkan nilai $t_{\text {hitung }}>t_{\text {tabel }}($ $>0.05)$, berarti ada pengaruh yang signifikan penerapan metode latihan single leg jump terhadap kemampuan plying shoot pemain bola tangan. Hasil tersebut membuktikan bahwa metode latihan single leg jump memiliki pengaruh terhadap kemampuan keterampilan plying shoot pemain bola tangan
\end{abstract}

Kata Kunci: latihan, single leg jump, plying shoot

\begin{abstract}
The research on the application of the single leg jump training method aims to prove its effect on the ability of plying shoot handball players. The research method uses an experimental method through a quantitative approach that is structured on the data description of the single leg jump training method of influence on the ability of plying shoot. The study design uses the One Group Pretest-Postest Design. The population of Physical Education Study Program Students, FKIP PGRI Adi Buana University Surabaya, while the sample of Physical Education students in the class of 2017 was determined purposively by 20 people. The results of hypothesis testing using t-test analysis, (sign. 0.05) and $d k=19$ turns out the $t_{\text {count }}$ was 2.26 and $t_{\text {table }}$ was 1.73. This shows the value of $t_{\text {acount }}>t_{\text {table }}(>0.05)$, meaning that there is a significant influence on the application of the single leg jump training method on the plying shoot ability of a handball player. These results prove that the method of single leg jump training has an influence on the ability of the plying shoot skills of handball players
\end{abstract}

Keywords: exercise, single leg jump, plying shoot. 


\section{PENDAHULUAN}

Permainan bola tangan sangat identik gerakannya antara permainan bola basket dan sepakbola. Permainan ini salah satu cabang olahraga yang belum begitu dikenal dan belum memasyarakat di Indonesia, tetapi ada dalam kurikulum sekolah. Permainan bola tangan dalam kurikulum masuk lingkup bahasan materi permainan bola besar seperti; permainan sepakbola, bola voli dan bola basket yang bertujuan sebagai olahraga pendidikan, olahraga rekreasi maupun olahraga prestasi. Permainan bola tangan dikatakan sebagai olahraga pendidikan dikarenakan tercantum di kurikulum sebagai bagian materi pelajaran pendidikan jasmani Olahraga kesehatan (PJOK) di sekolah termasuk kelompok permainan bola besar.

Permainan bola tangan dalam kurikulun PJOK masih menjadi olahraga pilihan sehingga masih sangat jarang diajarkan di sekolah (Abdurrochim \& Rachman, 2016). Sedangkan dikatakan olahraga rekreasi karena dapat dimainkan dalam mengisi waktu luang dengan berbagai variasi dan bentuk bermain. Unsur olahraga prestasi dalam permainan bola tangan digambarkan dengan adanya berbagai kejuaraan mulai dari tingkat regional, nasional maupun internasional. Permainan bola tangan termasuk olahraga beregu yang memiliki karakteristik dimainkan oleh 7 orang pemain yang berusaha memasukan bola ke gawang lawan (Kurniawan, 2012., Mustaqim, 2019). Selain itu permainan bola tangan dari segi teknik dasar bermain hampir sama dengan permainan bola basket, sedangkan dari bentuk lapangan hampir identik dengan lapangan permainan sepakbola. Menurut Kurniawan (2012) yang dikutip Mustaqim (2019), bola tangan adalah kombinasi antara olahraga basket dan sepakbola yang mengandalkan keterampilan tangan untuk memasukan bola ke gawang lawan. Lapangan permainan bola tangan berukuran $20 \times 40$ meter dimainkan oleh dua tim, terdiri dari 7 orang pemain setiap tim dengan waktu permainan $2 \times 30$ menit lamanya.

Permainan bola tangan dlihat dari karakteristiknya merupakan kombinasi antara permainan bola basket dan sepakbola. Karakteristik yang paling dominan adalah dari sisi teknik dasar bermain yang terdiri dari teknik dasar menggiring (dribling), melempar (passing), menangkap (cacthing) dan menembak (shooting). Salah satu teknik dasar yang sangat dominan perananannya dalam memenangkan pertandingan adalah teknik dasar menembak (shooting). Shooting merupakan bentuk gerakan melempar bola yang ditujukan ke arah gawang dengan tepat dan akurat. Teknik dasar menembak dalam permainan bola tangan yang paling banyak menghasilkan gol adalah teknik menembak sambil melayang (plying shoot). Plying shoot atau teknik menembak dengan gerakan sambil melayang yang dilakukan dalam permainan bola tangan dengan posisi menolak ke arah atas menghadap gawang sambil melayang (Mustaqim, 2019).

Gerakan plying shoot dalam bentuk lemparan bola secara melayang bertujuan memasukan bola ke arah gawang agar terarah dan akurat memerlukan unsur kekuatan dan kecepatan atau daya eksplosif sebagai komponen kemampuan fisik. Artinya untuk mengerahkan kekuatan dan kecepatan saat melakukan plying shoot harus memiliki tenaga dan daya ledak (exsplosive power) yang dapat menghasilkan gerak laju bola yang dilempar memiliki kekuatan dan kecepatan secara terarah dan akurat. Kemampuan plying shoot pada pemain bola tangan tersebut tidak terlepas dari komponen kondisi fisik yang peranannya sangat dominan saat bermain, karena setiap pemain bola tangan untuk menunjang kemampuan 
teknik dasarnya harus memiliki kemampuan kondisi fisik diantaranya; unsur kecepatan, kekuatan, kelentukan, kelincahan, power, daya tahan dan stamina yang baik. Komponen konsisi fisik yang sangat dominan dalam melakukan plying shoot adalah daya ledak (exsplosive power) seorang pemain. Bentuk latihan untuk melatih kemampuan eksplosif power seorang pemain bola tangan adalah melalui latihan plyometrik.

Latihan plyometrik pertama kali dikembangkan oleh Fred Wilt pada tahun 1975 yaitu seorang pelatih cabang olahrag atletik dari Amerika. Menurut Lubis (2013) dalam Cahyadi, Pujianto \& Arwin (2018) Secara harfiah istilah plyometrik berasal dari bahasa latin "plyometric". Kata plyo dan metrics, plyomteric diartikan sebagai peningkatan yang dapat diukur. Menurut Lumintuarso (2013) yang dikutip Cahyadi, Pujianto \& Arwin (2018), plyometrik adalah metode latihan untuk kekuatan kecepatan (power) dimana berat tubuh tubuh atlet itu sendiri digunakan sebagai beban utama berat. Latihan pliometrik bertujuan mengintegrasikan kekuatan maksimal yang telah dimiliki oleh atlet kedalam aplikasi gerakan cepat dan kuat sesuai dengan olahraga tertentu. Selain itu menurut Nurdiansyah dan Susilawati (2018), secara umum latihan plyometrik memiliki aplikasi yang sangat luas dalam kegiatan olahraga dan secara khusus latihan plyometrik sangat bermanfaat untuk meningkatkan power.

Oleh karena itu dapat dikatakan bahwa latihan plyometrik memiliki karakteristik kombinasi antara latihan eksentrik (isometrik) dan konsentrik (isotonik) yang menggunakan beban secara dinamis bertujuan meningkatkan daya ledak (exsplosive power). Salah satu metode latihan plyometrik untuk melatih keterampilan plying shoot adalah latihan plyometrik single leg jump. Single leg jump merupakan metode latihan plyometrik dimana gerakannya dilakukan dengan loncatan kedepan menggunakan salah satu kaki secara bergantian kanan dan kiri sebagai tumpuan. Loncatan ke depan dengan tumpuan satu kaki secara bergantian akan membangkitkan daya ledak. Bentuk latihan Single leg jump yang dilakukan berulang-ulang dengan tujuan menguatkan otot tungkai yang terintegrasi dengan unsur kekuatan dan kecepatan akan menghasilkan daya ledak. Daya ledak yang dihasilkan ini disebabkan kontraksi otot yang sangat kuat dari adanya pembebanan yang dapat menimbulkan regangan yang cepat dari otot-otot yang berkontraksi. Gaya gravitasi pada gerakan plyometrik bertujuan untuk menyimpan dan menghasilkan energi dalam otot dengan segera melepas energi yang berlawanan.

Hasil pengamatan pada setiap pemain bola tangan saat melakukan gerakan plying shoot kesalahan yang sering terjadi adalah masih rendahnya unsur daya ledak (exsplosive power) saat melakukan tolakan sebagai tumpuan untuk menghasilkan tenaga, sehingga saat menembakkan bola ke arah gawang unsur kekuatan dan kecepatan tidak maksimal dan arah bola tidak tepat (akurat). Sebagai upaya untuk mengatasi kesalahan tersebut yaitu dengan memberikan dan menerapkan metode latihan single leg jump yang bertujuan untuk menguatkan otot-otot tungkai bagian bawah (lower exstremity) yang dapat menghasilkan daya ledak (exsplosive power).

Berdasarkan hasil pengamatan tersebut, permasalahan penelitian yang menarik untuk diteliti yaitu mengenai metode latihan Single leg jump pengaruhnya terhadap kemampuan plying shoot pemain bola tangan. Metode latihan single leg jump adalah salah satu alternatif metode latihan untuk memudahkan pemain dalam melakukan gerakan melayang (plying) agar 
daya eksplosif pemain dapat ditingkatkan. Diterapkannya metode latihan single leg jump karena kemampuan lemparan atlet bola tangan sangat dipengaruhi oleh karakteristik antrometri yang baik dan kemampuan fisik yang prima (Lusiana, 2015 dalam Rohman, 2020), selain itu pemain bola tangan harus memiliki kemampuan kondisi fisik yang tinggi dalam kecepatan, kekuatan, kelincahan, daya tahan dan koordinasi (Mahendra, 2000 dalam Yulita, 2016). Sedangkan menurut Lusiana (2015), kemampuan lemparan pemain bola tangan sangat dipengaruhi oleh kekuatan dan kecepatan lemparan maupun akurasi lemparan dalam mencetak gol ke gawang lawan.

Oleh sebab itu kemampuan melempar bola seorang pemain bola tangan sangat dominan dan signifikan pengaruhnya dalam mengembangkan suatu permainan. Sehubungan dengan permasalahan tersebut, dalam penelitian ini peneliti telah meneliti mengenai penerapan metode latihan single leg jump pengaruhnya terhadap kemampuan single leg jump pemain bola tangan. Manfaat yang ingin dicapai dalam penelitian ini adalah dapat dijadikan landasan sebagai pedoman dan acuan bagi para guru PJOK dan para pelatih bola tangan sebagai role model metode latihan dalam menentukan dan mengembangkan keterampilan dan kemampuan plying shoot pemain bola tangan yang dibinanya.

\section{METODE PENELITIAN}

Metode eksperimen adalah salah satu metode yang banyak digunakan untuk penelitian Metode eksperimen menurut Sugiyono (2014), Bagaskara \& Suharjana (2018), adalah salah satu metode yang digunakan untuk mencari pengaruh perlakuan tertentu terhadap suatu kondisi yang dapat dikendalikan. Untuk mencari pengaruh tersebut, penelitian ini menggunakan metode pre-eksperimen. Metode pre-eksperimen. Menurut Arikunto (2013) yang dikutip Kurniawan \& Ramadan (2016), preeksperimen dipandang sebagai metode eksperimen tidak sebenarnya, karena belum memenuhi persyaratan seperti eksperimen ilmiah yang mengikuti peraturan tertentu. Oleh karena itu, alasan peneliti menggunakan pre-eksperimen atas pertimbangan berdasarkan sifat metode pre-eksperimen yaitu menguji cobakan sesuatu untuk mengetahui pengaruh dari suatu perlakukan (treatment)

Disain penelitian melalui pendekatan One Group Pretest-Postest Design dengan alasan disain ini dapat diketahui lebih tepat karena membandingkan sebelum diberi perlakuan (Sugiyono, 2014., Rohman, 2020). Skema penelitian dengan rancangan [ Pretest $\left(\mathrm{O}_{1}\right)$ - Treatmen $(\mathrm{X})$ - Post-test $\left.\left(\mathrm{O}_{2}\right)\right]$ artinya sebelum diberi perlakuan ada pre-test, kemudian treatment dan yang terakhir ada post-test.

Populasi penelitian mahasiswa Program Studi Pendidikan Jasmani, FKIP Universitas PGRI Adi Buana Surabaya yang dipilih sebagai subjek yang diteliti. Sampel adalah mahasiswa Program Studi Pendidikan Jasmani Angkatan 2017 yang memprogram Mata Kuliah Permainan Bola Tangan diambil secara purposif sampling berjumlah 20 Orang mahasiswa. Alat pengumpulan data tidak lepas dari penggunaan instrumen. Menurut Zakaria., Mudian, \& Riyanto (2018), Instrumen penelitian adalah alat ukur yang digunakan peneliti dalam pengumpulan data yang menghasilkan hasil lebih cermat, lengkap dan sistimatis sehingga lebih mudah diolah. Atas dasar konsep tersebut, penelitian ini menggunakan instrumen pengukuran keterampilan dasar flying shoot test yaitu tes menembak sambil melayang (Mustaqin, 2019). Menurut Susanto (2017), instrumen 
plying shoot test bertujuan mengukur keterampilan menembak secara berturut-turut dari tiga posisi; kiri, tengah, kanan (Susanto, 2017). Prosedur pelaksanaan tes dilakukan sebanyak 6 kali kesempatan menembak dari tiga posisi yaitu kiri, tengan, kanan yang berbeda jaraknya dengan bertumpu pada salah satu kaki sebagai dasar tolakan. Penilaian diambil dari hasil 6 kali melakukan tembakan ke arah gawang.

Teknik analisis data terbagi menjadi dua tahapan, yaitu tahapan pertama uji normalitas data menggunakan tes Kolmogorov-Smirnov dan homogenitas data menggunakan uji varian (uji-F). Pada tahap kedua dilakukan uji hipotesis dengan cara menganalisis melalui analisis uji-t menggunakan aplikasi SPSS versi 3.1.

\section{HASIL DAN PEMBAHASAN}

Lamanya penelitian dilaksanakan selama tiga bulan dengan jumlah pertemuan sebanyak 12 kali. Prosedur perlakuan (treatment) mengacu pada kaidah dan prinsip-prinsip latihan latihan pliometrik single leg jump. Menurut Sukadiyanto (2013) dalam Nurdiansya \& Susilawati (2018), prinsip latihan adalah salah satu upaya untuk meningkatkan kualitas latihan. Data hasil pengukuran flying shoot test yang meliputi data tes awal (pree-test) dan data tes akhir (post-test) selanjutnya dilakukan analisis data melalui dua tahap yaitu Pertama menguji normalitas dan homogenitas data. Sedangkan tahap kedua menguji hipotesis dengan cara menganalisis melalui analisis uji-t. Berikut ini hasil analisis pada tahap pertama dan kedua.
Tabel 1. Hasil Analisis Normalitas Data

\begin{tabular}{ccccc}
\hline \multirow{2}{*}{$\mathrm{N}$} & Instrumen & \multicolumn{2}{c}{$\begin{array}{c}\text { Kolmogorov- } \\
\text { Smirnov Test }\end{array}$} & $\begin{array}{c}\text { Sig.0.05 } \\
\text { tes }\end{array}$ \\
\cline { 3 - 4 } & & $\begin{array}{c}\text { Pre- } \\
\text { test }\end{array}$ & $\begin{array}{c}\text { Post- } \\
\text { test }\end{array}$ & \\
\hline \multirow{2}{*}{20} & $\begin{array}{c}\text { Plying } \\
\text { Shoot }\end{array}$ & 0.742 & 0.634 & 0.856 \\
\hline
\end{tabular}

Data pada Tabel 1, menunjukkan hasil analisis tes Kolmogorov-Smirnov diperoleh tes awal (pre-test) dan tes akhir (post-test) sebesar 0.742 dan 0.634 dengan signifikansi (sig.0.05) sebesar 0.856 ( > 0.05) berarti hasil analisis distribusi data adalah normal. Setelah itu dilanjutkan uji homogenitas data yang bertujuan agar data sampel memiliki varian yang sama. Berikut ini hasilnya uji homogenitas data tes.

Tabel 2. Hasil Analisis Homogenitas Data

\begin{tabular}{|c|c|c|c|}
\hline \multirow{2}{*}{$\mathrm{N}$} & \multirow{2}{*}{$\begin{array}{l}\text { Instrumen } \\
\text { tes }\end{array}$} & \multicolumn{2}{|c|}{ Uji-F } \\
\hline & & $\mathrm{F}_{\text {hitung }}$ & $\mathrm{F}_{\text {tabel }}$ \\
\hline 20 & $\begin{array}{l}\text { Plying } \\
\text { Shoot }\end{array}$ & 2.05 & 2.94 \\
\hline
\end{tabular}

Data di atas, menunjukkan nilai $\mathrm{F}_{\text {hitung }}$ sebesar 2.05 sedangkan $\mathrm{F}_{\text {tabel }}$ pada taraf signifikansi (sig.0.05) derajat kebebasan (df) $(20 ; 20)$ sebesar 2.94 hal ini berarti nilai $F_{\text {hitung }}<$ $\mathrm{F}_{\text {tabel }}(<0.05)$, artinya varian tes dinyatakan homogen.

Langkah selanjutnya setelah distribusi data dinyatakan normal dan varian sampel homogoen, maka dilakukan analisis uji hipotesis (uji-t) yang bertujuan membuktikan pengaruh metode latihan single leg jump terhadap kemampuan plying shoot pemain bola tangan. Berikut ini hasil uji hipotesis menggunakan analisis uji-t.

Tabel 3. Hasil Analisis Uji Hipotesis

\begin{tabular}{cccc}
\hline \multirow{2}{*}{$\mathrm{N}$} & \multirow{2}{*}{ Instrumen tes } & \multicolumn{3}{c}{ Uji-t } \\
\cline { 3 - 4 } 20 & Plying Shoot & $\mathrm{t}_{\text {hitung }}$ & $\mathrm{t}_{\text {tabel }}$ \\
\hline \multirow{2}{*}{2.26} & 1.73 \\
\hline
\end{tabular}


Dari data Tabel 3, menunjukkan $t$ hitung sebesar 2.26 sedangkan $t_{\text {tabel }}$ pada taraf nyata $($ sig.0.05) derajat kebebasan $(\mathrm{df})=19$ nilai $\mathrm{t}$ tabel Sebesar 1.73 berarti nilai $t_{\text {hitung }}>t_{\text {tabel }}$ (> 0.05), hal ini membuktikan bahwa penerapan metode latihan single leg jump ada pengaruhnya terhadap kemampuan Plying Shoot pemain bola tangan.

Atas dasar hasil analisis dan sesuai permasalahan penelitian dapat dibuktikan memberikan jawaban bahwa penerapan model latihan single leg jump memberikan pengaruh yang signifikan terhadap kemampuan plying shoot pemain bola tangan. Adanya pengaruh tersebut merupakan efek yang ditimbulkan selama melakukan metode latihan single leg jump secara teratur dan terprogram.

Mengacu pada hasil analisis tersebut, menunjukkan bahwa penerapan metode latihan single leg jump memberikan pengaruh pada kemampuan plying shoot pemain bola tangan. Adanya pengaruh kemampuan plying shoot tersebut, disebabkan metode latihan single leg jump (variabel bebas) menimbulkan efek pada kemampuan plying shoot (variabel terikat). Efek yang ditimbulkan tersebut diakibatkan oleh perlakuan (treatment) selama 12 kali pertemuan dengan menerapkan program latihan single leg jump secara kontinue. Menurut Pate (1984) yang dikutip Rohman (2018), bahwa latihan yang diberikan kurang lebih selama 6-8 minggu memberikan dampak peningkatan yang cukup berarti. Selain itu faktor yang menyebabkan meningkatnya kapasitas latihan adalah karena meningkatnya kapiler pada otot, yang menimbulkan peningkatan aktin dan miosin. Peningkatan ini menyebabkan perubahan biokimia terjadi di otot sehingga dapat meningkatkan ATP-PC yang berperan dalam kontraksi otot (Fox, 1988 dalam Rohman, 2018).

Gerakan latihan single leg jump secara kontinyu akan merangsang otot bagian tungkai seperti otot gastronemius dan femoris. Otot ini akan mengalami perubahan pada serabut otot yang disebabkan oleh latihan. Peningkatan serabut otot yang menyebabkan meningkatnya kekuatan dan kecepatan otot. Meningkatnya kekuatan kecepatan otot menimbulkan power atau daya ledak eksplosif pada tubuh. Menurut Sugiyanto \& Sudjarwo (1993) yang dikutip Supriyanto (2018), adanya daya eksplosif memungkinkan kerja otot atau sekelompok otot menghasilkan kerja fisik yang eksplosif. Hal ini ditentukan oleh kekuatan otot dan kecepatan rangsangan syaraf serta kecepatan kontraksi otot. Sebab menurut Kurniawan dan Ramadan (2016) Perpaduan antara kecepatan kekuatan merupakan perwujudan dari daya ledak. Oleh karena itu faktor yang berperan dalam pencapaian prestasi olahraga adalah faktor fisik terutama power otot tungkai (Cahyadi, Pujianto \& Arwin, 2018)

Faktor fisik merupakan faktor dominan dalam memainkan bola pada permainan tangan. Komponen kondisi fisik sangat dibutuhkan setiap pemain bola tangan agar dapat bermain dengan baik dalam setiap kompetisi yang diikuti. Salah satu faktor dominan yang harus dimiliki adalah kecepatan (speed) dan exsplosive power (Lusiana, 2015). Oleh karena itu latihan plyometrik adalah salah satu metode latihan untuk meningkatkan daya eksplosif. Latihan ini adalah bentuk latihan yang mengutamakan gerakan untuk memberikan rangsang tegangan otot secara mendadak agar terjadi kontraksi yang lebih kuat. Latihan pliometrik ini menghasilkan peningkatan daya ledak (Cahyadi, Pujianto \& Arwin, 2018). Menurut Irawan, Soegiyanto \& Hidayah (2017), latihan plyometrik 
merupakan latihan berbeban yang mampu meningkatkan kemampuan kekuatan, kecepatan, daya ledak dan kontrol motorik dengan mengikuti prinsip latihan yang benar dan sesuai. Menurut Pratiwi., Setijono \& Fuad (2018), latihan plyometrik berkonstribusi pada perubahan aktivitas lompat tegak (vertical jump) yang dapat mempengaruhi kecepatan, kekuatan atau power secara bersamaan dengan kesadaran gerak. Oleh karena itu secara khusus latihan plyometrik peranannya sangat dominan dalam berbagai aktivitas olahraga, hal ini seperti yang dikatakan Utamayasa (2020), efek spesifik latihan plyometrik pada kinerja dalam berbagai jenis lompatan sangat penting dalam berbagai kegiatan olahraga. Salah satu metode latihan plyometrik yang peneliti terapkan dalam mengembangkan kemampuan plying shoot adalah metode latihan plyometrik single leg jump.

Latihan single leg jump yang diberikan dalam proses penelitian ini merupakan salah satu gerakan latihan plyometrik karena menurut Rahadian, Agustan \& Mulyana (2016), metode latihan yang paling efektif untuk mengembangkan explosive power adalah latihan plyometrik Latihan plyometrik merupakan bentuk metode latihan kekuatan kecepatan (power) yang bertujuan menghubungkan kekuatan maksimal kedalam aplikasi gerak yang cepat dan kuat sesuai dengan olahraga tertentu (Lumintuarso, 2013 dalam Cahyadi, Pujianto \& Arwin, 2018). Mengacu pada pembahasan dan konsep tersebut, temuan penelitian membuktikan bahwa metode latihan plyometrik single leg jump memberikan pengaruh yang signifikan terhadap kemampuan plying shoot pemain bola tangan

\section{KESIMPULAN}

Mendasari hasil analisis dan pembahasan tersebut, penulis menyimpulkan hasil penelitian yaitu metode latihan plyometrik single leg jump ada pengaruhnya pada kemampuan pemain bola tangan dalam melakukan flying shoot. Artinya bahwa penerapan bentuk latihan dengan menggunakan metode latihan single leg jump akan mempengaruhi kemampuan keterampilan pemain bola tangan dalam melakukan teknik tembakan melayang (flying shoot).

\section{REFERENSI}

Abdurrochim, Muhamad., Rachman, Hari Amirullah., (2016), Pengembangan Model Permainan Bolatangan Untuk Anak Usia Sekolah Dasar Kelas Atas., Jurnal Keolahragaam, 4 (1), 60-73

Bagaskara., Bayu, Adhitya., Suharjana., (2019)., Pengaruh Latihan Plyometric Box Jump dan Plyometric Standing Jump Terhadap Kemampuan Vertical Jump Pada Atlet Klub Bola Voli, Jurnal Medikora, 18 (2), 64-69

Cahyadi, Melfi., Pujianto, Dian., \& Arwin., (2018)., Pengaruh Latihan Plyometric di Pasir Terhadap Power Otot Tungkai Siswi di SMKN1 Kota Bengkulu Tahun 2017/2018., Jurnal Kinestetik, 2 (1), 67-74

Irawan, Rudi Prida., Soegiyanto \& Hidayah, Taufiq., (2017)., Pengaruh Latihan Plyometrics dan Kekuatan Tangan terhadap Hasil Kecepatan Panjat Tebing di SMK Negeri 1 Nusawungu Kabupaten Cilacap, Journal of Physical Education and Sports (JPES)., 6 (1), 83-87

Kurniawan, Feri. (2012). Buku Pintar

Olahraga. Jakarta : Laskar Askara.

Kurniawan., Ramadan, Gilang., (2016)., Pengaruh Latihan Plyometric Terhadap Hasil Smash pada Ekstrakurikuler 
Bolavoli, Juara: Jurnal Olaharaga, 2 (1), $110-118$

Lusiana., (2015), Faktor Pengaruh Kemampuan Lemparan (Shooting) Pada Atlet Handball Putri Jawa Tengah., Journal of Physical Education and Sports (JPES), 2 (2), 65-68

Mustaqim, Enjang Ahmad., (2019)., Pengaruh Latihan Push Up dan Pull Up Terhadap Hasil Flying Shoot dalam Permainan Bola Tangan Pada Mahasiswa Komunitas Bola Tangan Unisma Bekasi, Jurnal Genta Mulia, 9 (1), 52-62

Nurdiansyah, Susilawati., (2018)., Pengaruh Latihan Plyometric Hurdle Hopping Terhadap Kemampuan Daya Ledak Otot Tungkai., Multilateral: Jurnal Pendidikan Jasmani dan Olahraga, 17 (1), 29-34

Rahadian , Wildan., Agustan, Boby \& Mulyana, Nanang., (2018)., Pengaruh Latihan Plyometric Terhadap Hasil Smash dalam Permainan Bolavoli., Jurnal Kepelatihan Olahraga (JKO), 8 (2), 1-10

Rohman, Ujang., (2018)., Metode Pembelajaran Permainan Bola Tangan dengan Menggunakan Latihan Ladder Drill Hop Scotch Pengaruhnya Terhadap Kemampuan Agility Bermain Bola., Jurnal Buana Pendidikan., 14 (26), 136-142

Rohman, Ujang., (2020)., Metode Lempar Tangkap Bola Statis dan Dinamis: Implikasinya dalam Meningkatkan Pembelajaran Gerak Dasar Passing Permainan Bola Tangan, Jurnal Menssana 5 (1), 1-8
Sugiyono., (2014)., Metode Penelitian Pendidikan, Bandung; Penerbit Alfabeta

Supriyanto., (2018)., Pengaruh Metode Latihan Plyometric dan Latihan Beban Dengan Kecepatan Reaksi Terhadap Power Otot Tungkai Pemain Bolavoli Putra, Gelanggang Olahraga: Jurnal Pendidikan Jasmani dan Olahraga 2 (1), 176-189

Susanto, Ermawan., (2017)., Pengembangan Tes Keterampilan Dasar Olahraga Bola Tangan Bagi Mahasiswa, Jurnal Penelitian dan Evaluasi Pendidikan., 21 (1), 116-125

Utamayasa, I Gede Dharma., (2018)., Efek Latihan Multiple Box Jump Terhadap Peningkatan Power Otot Tungkai, Jurnal Pendidikan Kesehatan Rekreasi., 6 (1), 1-8

Yulita., (2016)., Pengembangan Permainan Bola Tangan Gawang Pantul untuk Pembelajaran Penjasorkes., Jurnal Pendidikan Jasmani Kesehatan dan Rekreasi(Penjaskesrek)., 3 (2), 24-31

Zakaria, Gumilar., Mudian, Deni \& Riyanto, Pulung., (2019)., Pengaruh Latihan Plyometrics Jump To Box Terhadap Peningkatan Power Tungkai Siswa Kelas X Pada Permainan Bola Voli., Jurna lmiah Biormatika., 5 (1), 1-8

Zarra Pratiwi, Febrianti, Setijono, Hari \& Fuad, Yusuf.,(2019)., Pengaruh Latihan Plyometric Front Cone Hops dan Counter Movement Jump Terhadap Power dan Kekuatan Otot Tungkai., Jurnal Sportif., 4 (1), 105 118 